\title{
Differential Effects of Two Widely Used Solvents, DMSO and Ethanol, on the Growth and Recovery of Trypanosoma cruzi Epimastigotes in Culture
}

\author{
Ana María Cevallos, Juliana Herrera, Imelda López-Villaseñor, Roberto Hernández* \\ Departamento de Biología Molecular y Biotecnología, Instituto de Investigaciones Biomédicas, Universidad Nacional Autónoma de México, \\ Apartado Postal 70-228,CP 04510, Ciudad de México, México
}

\begin{abstract}
Trypanosoma cruzi is the etiological agent of Chagas disease. Epimastigote forms of $T$. cruzi can be readily cultured in axenic conditions. Ethanol and dimethyl sulfoxide (DMSO) are commonly used solvents employed as vehicles for hydrophobic compounds. In order to produce a reference plot of solvent dependent growth inhibition for T. cruzi research, the growth of epimastigotes was analyzed in the presence of different concentrations of ethanol (0.1-4.0\%) and DMSO (0.5-7.5\%). The ability of the parasites to resume growth after removal of these solvents was also examined. As expected, both ethanol and DMSO produced a dose-dependent inhibition of cellular growth. Parasites could recover normal growth after 9 days in up to $2 \%$ ethanol or $5 \%$ DMSO. Since DMSO was better tolerated than ethanol, it is thus recommended to prefer DMSO over ethanol in the case of a similar solubility of a given compound.
\end{abstract}

Key words: Trypanosoma cruzi, kinetoplastidia, solvent, DMSO, ethanol, drug screening

Trypanosoma cruzi is a parasitic protozoon of biomedical importance. This pathogen causes Chagas' disease, which is also referred to as American trypanosomiasis [1]. Although this condition is contracted primarily in Latin America, large-scale population migrations to other latitudes and continents have spread Chagas' disease around the globe [2]. The treatment of this disease is complicated: benznidazole and nifurtimox are the only available drugs, and both produce severe side effects [3]. The search for new treatments against this parasite is an on-going topic for research [4-7].

Similar to other protozoa, T. cruzi presents a complex life cycle in 2 types of hosts, an invertebrate vector and a vertebrate host (humans in the case of Chagas' disease). The epimastigote is the extracellular dividing form that colonizes the digestive tract of the insect vector [8], and this stage of the parasite can be cultured in axenic media. With a doubling time of approximately $24 \mathrm{hr}$, T. cruzi epimastigotes can grow to high cellular densities (over 50 million cells/ml). This growth ability has been an asset for molecular and biochemical analyses of

- Received 6 September 2016, revised 15 December 2016, accepted 3 January 2017.

*Corresponding author (robertohf@biomedicas.unam.mx)

(c) 2017, Korean Society for Parasitology and Tropical Medicine

This is an Open Access article distributed under the terms of the Creative Commons Attribution Non-Commercial License (http://creativecommons.org/licenses/by-nc/4.0) which permits unrestricted non-commercial use, distribution, and reproduction in any medium, provided the original work is properly cited. this protozoon and also makes it the stage of choice for screening potential therapeutic drugs.

In laboratory bioassays, many of the drugs used to either block or activate metabolic pathways, or to evaluate toxicity to organisms, have low water solubility and need to be dissolved in organic solvents prior to addition into experimental systems [9]. The most widely used solvents are dimethyl sulphoxide (DMSO) and ethanol. DMSO is a dipolar aprotic solvent that can solubilize many otherwise poorly soluble polar and nonpolar molecules [10]. In spite of their widespread use, ethanol and DMSO are known to affect the metabolism and the viability of cells, effects that are frequently ignored. For example, DMSO is a substrate for NADPH-dependent microsomal-metabolising enzymes [11], and ethanol is a substrate for alcoholmetabolizing enzyme systems [12]. Under these circumstances, the direct effects of DMSO and ethanol on the growth ability of T. cruzi epimastigotes in culture represent an important consideration that has not been systematically evaluated.

The aim of this work was to provide a reference tool of the effects of increasing amounts of DMSO and ethanol on the growth of T. cruzi epimastigotes, not only during their exposure to the solvent but also after its withdrawal from the culture. This information should be useful when deciding the solvent of choice and its concentration for biochemical assays. The data here presented show that the growth of epimastigotes 
A

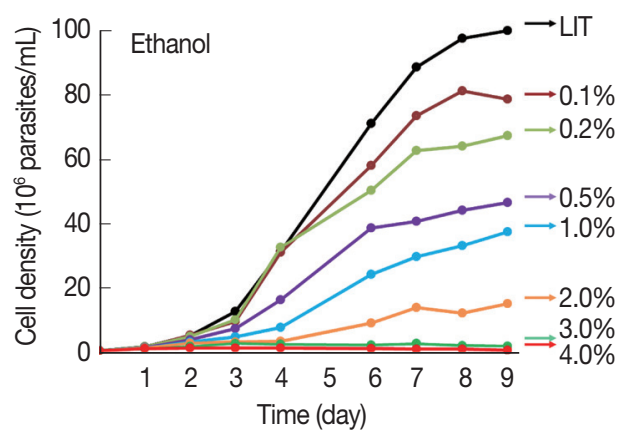

C

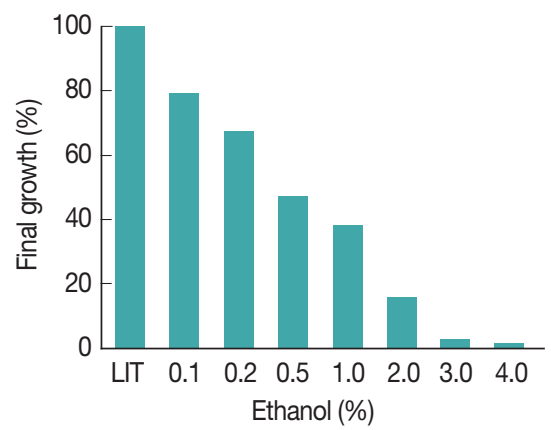

$\mathrm{B}$
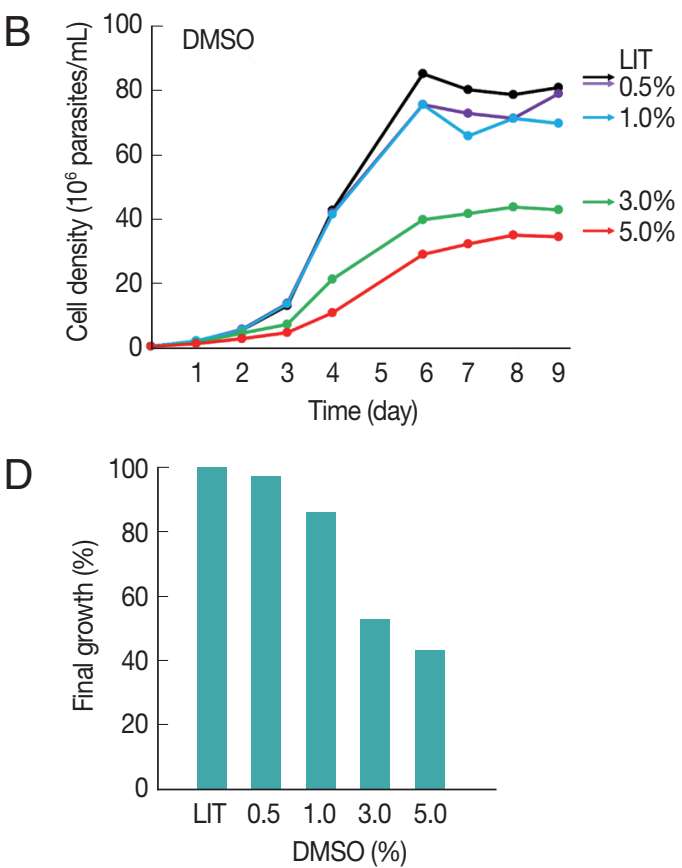

Fig. 1. Effects of ethanol and DMSO on T. cruzi growth. The growth of T. cruzi epimastigotes was periodically monitored for 9 days, as indicated. All cultures were started at an initial cellular concentration of $1 \times 10^{6}$ parasites $/ \mathrm{ml}$. LIT medium without solvent was used as a control. (A) Growth curves of epimastigotes cultured in different ethanol concentrations, as indicated. (B) Growth curves of epimastigotes cultured in different DMSO concentrations, as indicated. Plotted values represent the arithmetic means from 3 independent experiments. (C, D) Final cellular density of 9 day-old epimastigotes cultured in the presence of different amounts of the indicated solvents, relative to the solvent-free LIT growth controls.

was impaired with small concentrations of ethanol, whereas DMSO was better tolerated.

T. cruzi epimastigotes (CL-Brener strain) were axenically cultured at $28^{\circ} \mathrm{C}$ in liver infusion tryptose medium (LIT) [13] supplemented with $25 \mathrm{mg} / \mathrm{L}$ hemin (Sigma-Aldrich Química, Mexico City, Mexico) and 10\% fetal calf serum. In order to obtain reproducible results, the cellular population was homogenized by maintaining parasites in exponential phase of growth for at least 3 cycles (that is, not allowing them to reach densities greater than $30 \times 10^{6}$ cells per $\mathrm{ml}$ ), before the start of the actual time course analysis. The tested conditions were as follows: a 10-mL aliquot from a master culture containing 1 million epimastigotes per $\mathrm{ml}$ was placed in $25-\mathrm{cm}^{2}$ polystyrene cell culture flasks (Corning Incorporated, Mexico City, Mexico). Absolute ethanol (J.T. Baker ${ }^{\circledR}$, Xalostoc, Mexico) was added in different concentrations in the range of $0.1 \%$ to $4 \%$ and incubated at $28^{\circ} \mathrm{C}$ for up to 9 days, and the number of cells was estimated by hemocytometer counting (Fig. 1A). Similar growth curves were generated in the presence of DMSO at concentrations ranging from $0.5 \%$ to $5 \%$ (Fig. 1B). Each of the growth curves was repeated at least 3 times. A reference growth curve of cells cultured without any solvent was always included (LIT). At all concentrations tested, ethanol produced a dosedependent long-term growth reduction effect (Fig. 1A). The effect on the growth of epimastigotes was observed only after 3 days of incubation probably implying a time-dependent cumulative toxic effect of this solvent (or a derived metabolic product). No growth was observed at concentrations of 3\% ethanol and above. Similarly, DMSO also inhibited growth although the effect was observed at higher concentrations than those observed for ethanol (Fig. 1B). Interestingly, after 9 days of culture, DMSO was better tolerated than ethanol; cell density in $5 \%$ DMSO was about $50 \%$ of the control. In contrast, no increase in cell density was observed in the presence of 3\% ethanol and above (Fig. 1C, D). It is worth to mention that when the concentration of DMSO was increased to $7.5 \%$, the parasites suffered severe morphological alterations and died within $48 \mathrm{hr}$ (data not shown).

We then evaluated the ability of parasites to resume normal growth after the removal of the solvents. For this, 9 day-old cultures grown in the presence of the solvents were washed in PBS (pH 7.2) and placed in fresh LIT medium without the sol- 
A

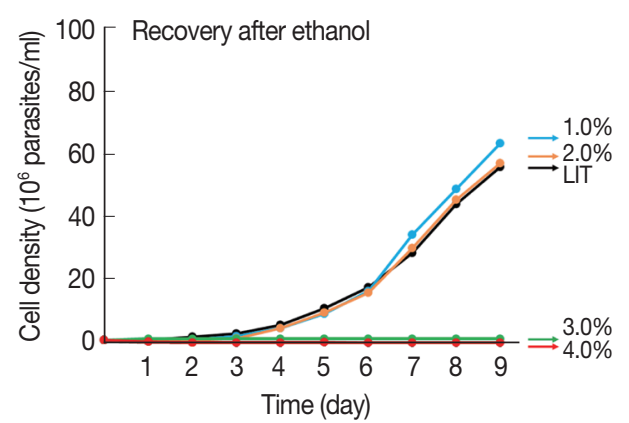

B

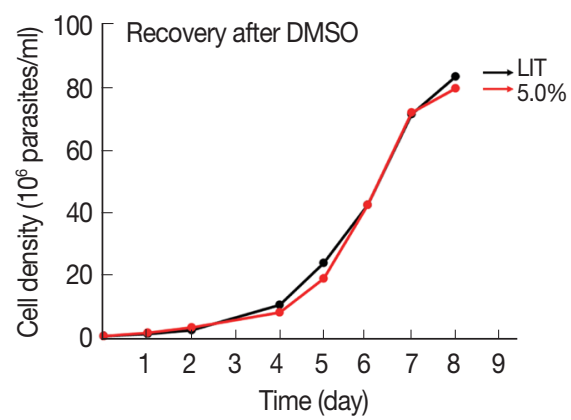

Fig. 2. Growth recovery of T. cruzi epimastigotes after treatment with either ethanol (A) or DMSO (B). Nine day-old epimastigote cultures, pre-grown in the presence of the indicated solvents, were washed with PBS and placed in solvent-free LIT medium at an adjusted cellular density of 1 million parasites per ml. Control cultures of cells previously grown in LIT medium were also included. Cellular growth was monitored at the indicated times. Plotted values represent the means of at least 2 independent experiments.

vent, all adjusted to a cellular density of 1 million parasites per $\mathrm{ml}$ to initiate the recovery cultures. Parasite cultures grown in up to $2 \%$ ethanol were able to regrow at a similar rate as the control immediately after the removal of the solvent, while parasites grown in 3 and 4\% ethanol completely lost their ability to regrow (Fig. 2A). In contrast, the epimastigotes grown for 9 days in 5\% DMSO resumed normal growth after the removal of the solvent (Fig. 2B).

Although an analysis of the cellular mechanisms affected by ethanol or DMSO in the T. cruzi epimastigote culture medium was not addressed in this work, it is worth noting that both solvents are known to have a wide variety of cellular targets, and that they are involved in different metabolic pathways $[11,12,14,15]$. Ethanol is known to inhibit growth, most likely due to an imbalance in the production of NAD/NADH, accumulation of acetaldehyde, and deactivation of replicative processes; in addition to metabolic consequences, the effect of ethanol on the membranes and displacement of cell-bound water have also been documented [16].

It has been reported that DMSO has a wide variety of effects, depending on the host and the concentration used. DMSO readily crosses most animal membranes, and is easily absorbed through the skin [14]. It has been shown that DMSO induces the differentiation of mouse, rat, and human leukemic cells at doses that range between 1-2\% [17-19]. Also, DMSO exerts a marked inhibitory effect on a broad range of bacteria and fungi at concentrations likely to be encountered in the antimicrobial testing programmes used by industry [20].

In conclusion, the effect of both ethanol and DMSO in biological systems is in itself an important area of research, and their contribution to the pharmacological effects of different drugs is frequently underestimated. In this work, we show that growth of T. cruzi epimastigotes is less affected by DMSO in comparison to ethanol. We consider that the work presented here will be useful in the design and interpretation of experiments involving the testing of drugs dissolved in these organic solvents.

\section{ACKNOWLEDGMENTS}

The technical assistance from Karla López-Pacheco is acknowledged. This work was partially supported by grants from Consejo Nacional de Ciencia y Teconología (CONACyT) 99062 and Programa de Apoyo a Proyectos de Investigación e Innovación Tecnológica (PAPIIT DGAPA UNAM) IN201616, Mexico.

\section{CONFLICT OF INTEREST}

We have no conflict of interest related to this work.

\section{REFERENCES}

1. Köberle F. Chagas' disease and Chagas' syndromes: the pathology of American trypanosomiasis. Adv Parasitol 1968; 6: 63-116.

2. Weiss LM, Tanowitz HB. Preface to Chagas disease. Adv Parasitol 2011; 76: xxi-xxvi.

3. Bern C, Montgomery SP, Herwaldt BL, Rassi A Jr, Marin-Neto JA, Dantas RO, Maguire JH, Acquatella H, Morillo C, Kirchhoff LV, Gilman RH, Reyes PA, Salvatella R, Moore AC. Evaluation and treatment of Chagas disease in the United States: a systematic review. JAMA 2007; 298: 2171-2181.

4. Díaz-Urrutia CA, Olea-Azar CA, Zapata GA, Lapier M, Mura F, Aguilera-Venegas B, Arán VJ, López-Múñoz RA, Maya JD. Biolog- 
ical and chemical study of fused tri- and tetracyclic indazoles and analogues with important antiparasitic activity. Spectrochim Acta A Mol Biomol Spectrosc 2012; 95: 670-678.

5. Vigueira PA, Ray SS, Martin BA, Ligon MM, Paul KS. Effects of the green tea catechin ( )-epigallocatechin gallate on Trypanosoma brucei. Int J Parasitol Drugs Drug Resist 2012; 2: 225-229.

6. Lim KT, Zahari Z, Amanah A, Zainuddin Z, Adenan MI. Development of resazurin-based assay in 384-well format for high throughput whole cell screening of Trypanosoma brucei rhodesiense strain STIB 900 for the identification of potential anti-trypanosomal agents. Exp Parasitol 2016; 162: 49-56.

7. Simões-Silva MR, Nefertiti AS, De Araújo JS, Batista MM, Da Silva PB, Bahia MT, Menna-Barreto RS, Pavão BP, Green J, Farahat AA, Kumar A, Boykin DW, Soeiro MN. Phenotypic screening in vitro of novel aromatic amidines against Trypanosoma cruzi. Antimicrob Agents Chemother 2016; 60: 4701-4707.

8. Tyler KM, Engman DM. The life cycle of Trypanosoma cruzi revisited. Int J Parasitol 2001; 31: 472-481.

9. El Jay A. Toxic effects of organic solvents on the growth of Chlorella vulgaris and Selenastrum capricornutum. Bull Environ Contam Toxicol 1996; 57: 191-198.

10. Galvao J, Davis B, Tilley M, Normando E, Duchen MR, Cordeiro MF. Unexpected low-dose toxicity of the universal solvent DMSO. FASEB J 2014; 28: 1317-1330.

11. Gerhards E, Gibian H. The metabolism of dimethyl sulfoxide and its metabolic effects in man and animals. Ann N Y Acad Sci 1967; 141: 65-76.
12. Teschke R, Hasumura Y, Lieber CS. Hepatic microsomal alcoholoxidizing system. Affinity for methanol, ethanol, propanol, and butanol. J Biol Chem 1975; 250: 7397-7404.

13. Camargo EP. Growth and differentiation in Trypanosoma cruzi. I. Origin of metacyclic trypanosomes in liquid media. Rev Inst Med Trop Sao Paulo 1964; 6: 93-100.

14. Jacob SW, Herschler R. Pharmacology of DMSO. Cryobiology 1986; 23: 14-27.

15. Harris RA, Trudell JR, Mihic SJ. Ethanol's molecular targets. Sci Signal 2008; 1: re7

16. Jones RP. Biological principles for the effects of ethanol. Enzyme Microb Technol 1989; 11: 130-153.

17. Friend C, Scher W, Holland JG, Sato T. Hemoglobin synthesis in murine virus-induced leukemic cells in vitro: stimulation of erythroid differentiation by dimethyl sulfoxide. Proc Natl Acad Sci USA 1971; 68: 378-382.

18. Kluge N, Ostertag W, Sugiyama T, Arndt-Jovin D, Steinheider G, Furusawa M, Dube SK. Dimethylsulfoxide-induced differentiation and hemoglobin synthesis in tissue cultures of rat erythroleukemia cells transformed by 7,12-dimethylbenz(a)anthracene. Proc Natl Acad Sci USA 1976; 73: 1237-1240.

19. Collins SJ, Ruscetti FW, Gallagher RE, Gallo RC. Terminal differentiation of human promyelocytic leukemia cells induced by dimethyl sulfoxide and other polar compounds. Proc Natl Acad Sci USA 1978; 75: 2458-2462.

20. Basch H, Gadebusch HH. In vitro antimicrobial activity of dimethylsulfoxide. Appl Microbiol 1968; 16: 1953-1954. 